\title{
An Analysis on the US New Media Public Diplomacy Toward China on WeChat Public Account
}

\section{Zhao Genga}

\begin{abstract}
Nowadays, with the development of the Internet, especially the mobile Internet, the appearance of WeChat has a deep influence on the communication among people. WeChat public accounts have changed a lot to the experience of getting information for people of all ages at the same time. As a new platform for public diplomacy, many foreign embassies and consulates in China have built their own public accounts of WeChat. These public accounts have become a new type of media to learn about these countries' culture, society, and so on. The paper takes the WeChat public account of the US embassy in China as an example, collecting information during a period of time and summarizing their characteristics and revelations. As a model of new media public diplomacy, WeChat public accounts have a silent transforming influence of public diplomacy. In addition, the new media public diplomacy plays an important role in promoting the development of China's public diplomacy strategy, which increasingly becomes a useful supplement to China's foreign policy. Therefore, in the mobile Internet era, the research of new media public diplomacy has an important implication.
\end{abstract}

\section{Keywords}

WeChat public accounts, new media, public diplomacy, the US embassy in China

Nowadays, as the large development of Internet, public diplomacy in cyberspace is becoming more and more attractive. Especially with the popularity of mobile Internet, the connotation and extension of public diplomacy has been extended. The most special aspect of public diplomacy is that the goal is to transfer the positive and favorable information to the public in order to protect the interests of the country's diplomacy (Zhou 2013). The appearance of many kinds of new media platform marks that the development of public diplomacy can be made in a new way. Some embassies of foreign countries in China have registered their official accounts in Sina Weibo, Renren, WeChat public accounts, and so on. It will play a more and more important role in developing public diplomacy in China and enhancing the understanding of Chinese people to foreign countries. In recent years, the popularity of WeChat has greatly changed the methods of Chinese people getting information, making communication more and more convenient. Besides, as a new platform in new media age, the appearance of WeChat public accounts lets every individual and group become media publisher.

aShanghai International Studies University, China

\section{Correspondent Author:}

Zhao Geng, School of International Relations and Public Affairs, Shanghai International Studies University, No. 550, West Da Lian Road, Shanghai, China, 200083 
Developing public diplomacy by WeChat public accounts, the US embassy in China has walked in front of other countries. It has become an important window about holding many kinds of activities and America achieves its goal in developing public diplomacy to Chinese common people, especially Chinese young people. Therefore, developing public diplomacy in this new media platform can bring a large significance to China's foreign strategy.

The paper will analyze the pushed information from the WeChat public account of the US embassy in China, getting some points of the new changes and new thinking about developing public diplomacy. Therefore, it can bring some enlightenment toward China's public diplomacy and soft power in international society.

\section{THE RELATIONSHIP BETWEEN NEW MEDIA AND PUBLIC DIPLOMACY}

As the development of Internet technology, the new media becomes more and more popular. According to the definition from Wikipedia, new media most commonly refers to content available on-demand through the Internet, accessible on any digital device, usually containing interactive user feedback and creative participation. Common examples of new media include websites such as online newspapers, blogs, or wikis, video games, and social media ${ }^{1}$. The birth of new media must be attributed to the development of Internet. Especially with the popularity of mobile Internet, new media has become an important media to get information for individuals. The concept of public diplomacy is to express the communication and interaction between a country's government and foreign people.

In 1987, the Dictionary of International Relations Terms edited by U.S. Department of State defined public diplomacy that:

Government-Sponsored programs intended to inform or influence public opinion in other countries; The chief instruments of public diplomacy are publications, motion pictures, cultural exchanges, and radio and television; The United States has, for instance, used short-wave radio to provide information to closed societies; The United States Information Agency is responsible for the U.S. Government's overseas information and cultural programs, including the Voice of America ${ }^{2}$.

About the definition of public diplomacy, Tuch defined public diplomacy as "a government's process of communication with foreign publics in an attempt to bring about understanding for its nation's ideas and ideals, its institution and culture, as well as its national goals and policies". Frederick added information about specific content: "activities, directed abroad in the fields of information, education, and culture, whose objective is to influence a foreign government, by influencing its citizens" (Gilboa 2008: 57).

With time flying, the concept of public diplomacy has changed. The subject of developing public diplomacy is no longer just government agency. The subject of developing public diplomacy contains diplomatic departments, besides, non-governmental organization such as folk groups, universities, research institutions, media, and individuals.

Today, in the Internet era, the appearance of new media gives a new meaning of public diplomacy. Public diplomacy can be regarded as approach between a country's government and non-governmental organizations to communicate culture, ideology, society condition, foreign policy, and so on in many different ways including new media. It can enhance mutual understanding and it is helpful to the institution, foreign policy, and culture's implement, reaching the goal of friendly exchanges. It can be seen from the above. The concept of public diplomacy originated in America, at the same time, it developed as serving for American foreign policy.

New media is the communication medium with the help of digital technology, network technology, and mobile communication technology. Therefore, in 
new media time, the nature of diplomacy is the digitally diplomatic form which is based on the Web 2.0 (Dong and Sun 2012).

There is a common ground between the new media diplomacy and public diplomacy. The traditional public diplomacy is only initiated by the government and it is unidirectional. However, today's public diplomacy is bi-directional. As many kinds of mobile digital devices are cheap, the users' social coverage is extensive. People get a lot of information in real time. Therefore, in the face of such a new media era, the expansion of public diplomacy cannot leave the field of the platform.

In the information age, especially the wide application and popularization of mobile Internet has opened up a new field for the development of public diplomacy. Making full use of new media like WeChat public account will bring active image. By the new method, new media public diplomacy can benefit the national diplomatic strategy and improve the national soft power.

\section{THE CURRENT SITUATION IN WECHAT PUBLIC ACCOUNT OF THE US EMBASSY IN CHINA}

After comparing the frequency and quality of the content in embassies and consulates' WeChat public accounts, the embassy of the US public account is better than others. The information before 2015 is almost notices of activities in embassy, but since 2015, the information about American politics, economy, culture, and society is more and more. The author will analyze the characteristic afterwards ${ }^{3}$.

The embassy of the US public account began to post information since June 27, 2013. The author selected the information from August 1, 2014 to July 31, 2015 as samples. He classified information as "The situation of America", "Embassy news", "The White House news", "Lectures", "Film and television show", "Embassy notice", "Information releasing of
Beijing American Center", "Display information", "Informal discussion", "English writing training" and "Others". To sum up, there are 11 categories. It can be seen in Table 1 and Figure $1^{4}$.

It can be seen from Table 1. From August 1, 2014 to July 31,2015 , the embassy WeChat public account has issued 427 pieces of information. It issued 1.17 per day on average. Comparing with other diplomatic institutions' WeChat public accounts, releasing information frequency of the embassy of the US is higher than others. "Lectures" and "The situation of America" take the main parts of the total releasing information, $40.52 \%$ and $26.70 \%$ respectively.

In lecture activities, it has taken a major part about American education, politics, society, and so on. Besides, in this part, it has formed a column with regularity and brand such as "Football Weekend". In other parts like informal discussion, for example, Chinese and American students communicate together in the activity called "Student Coffee Hour".

Regular and themed activities play a role in activities releasing of embassy's WeChat public account. For example, films showing activities occupy a large part in "Film and television show". The films are almost Oscar winning films and other classic American films. After showing films, the staff members of Beijing American Center could communicate with the audiences. The regular mode promotes the development of activities in Beijing American Center and it has formed a brand effect in the US public diplomacy in China.

In January 2015, information about "The situation of America" came to WeChat public account of the embassy. Analyzing the information in samples by month, "The situation of America" has taken about one third of releasing information. It reflects that the United States' public diplomacy in China is always pursuing new breakthrough and looking for new areas.

In this part information, the articles mainly talk about America in politics, economy, history, society, culture, and other aspects, and they also have formed 
Table 1. Content Publishing Statistics on WeChat Public Account of the US Embassy in China (August 1, 2014-July 31, 2015)

\begin{tabular}{|l|l|}
\hline Content releasing (categories) & Number (unit: time) \\
\hline The situation of America & 114 \\
\hline Embassy news & 12 \\
\hline The White House news & 15 \\
\hline Lectures & 173 \\
\hline Film and television show & 28 \\
\hline Embassy notice & 3 \\
\hline Information releasing of Beijing American Center & 13 \\
\hline Display information & 6 \\
\hline Informal discussion & 30 \\
\hline English writing training & 25 \\
\hline Others & 8 \\
\hline Total & 427 \\
\hline
\end{tabular}

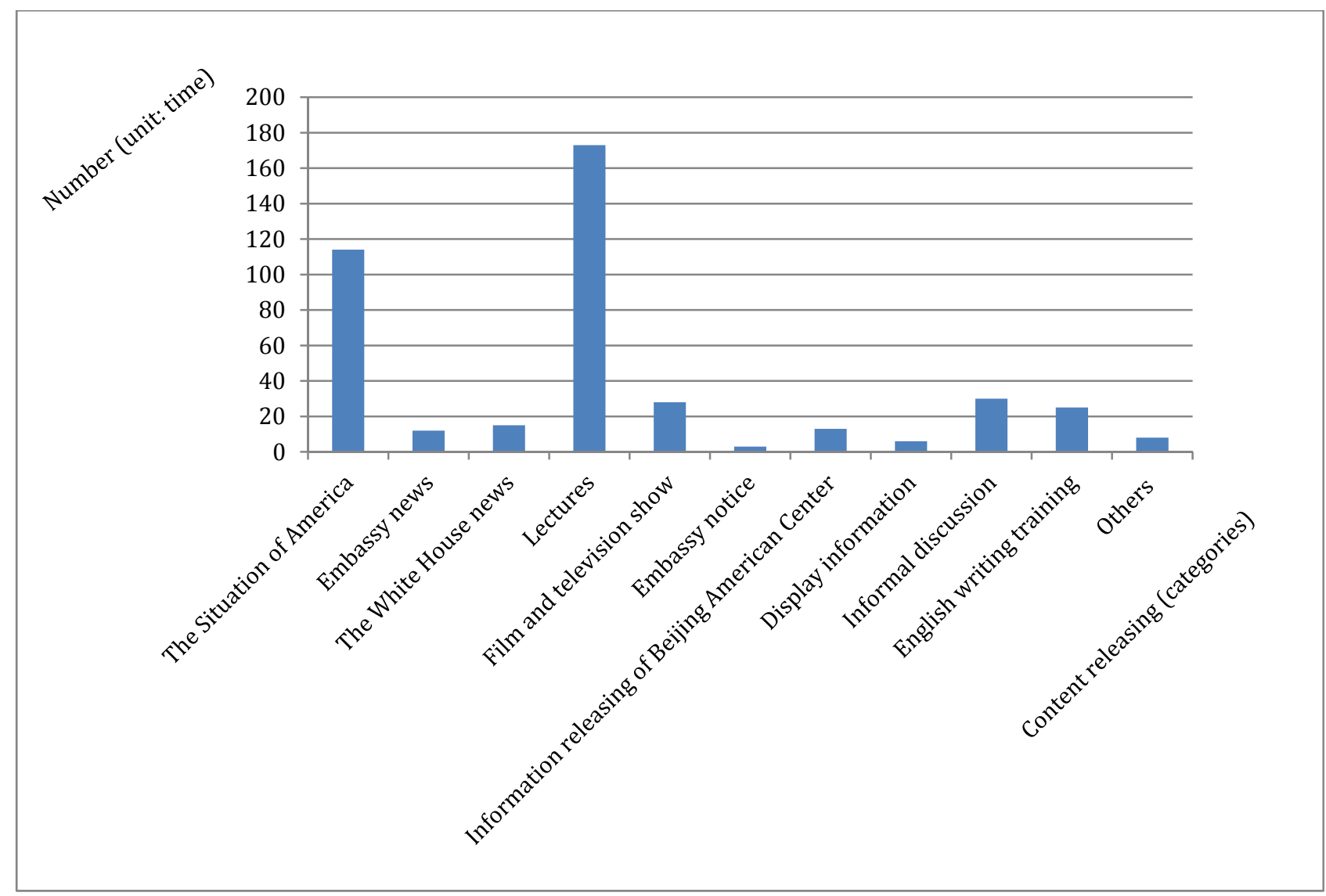

Figure 1. Content Publishing Statistics on WeChat Public Account of the US Embassy in China (August 1, 2014-July 31, 2015). 
regularly theme releasing such as "American History Series". Besides, the embassy of the US pays attention to the themes to show American spirits such as equal rights for homosexuals, racial equality, human rights protection, and so on. In this way, America conveys American spirit and ideology to Chinese people indirectly. This potential way does not interfere with the sensitive issues between China and the United States on human rights and democracy. But it promotes the superiority of American spirit to Chinese people potentially. It shows that the US public diplomacy focuses on the details and the value orientation.

To sum up, comparing with the official website and official Weibo, as a platform of promoting non-governmental exchanges, the public account of the embassy plays a different role. With this media, the US spreads its soft power to more and more WeChat subscribers, especially more and more Chinese young people.

Now, public account of American embassy has become a role model in embassies and consulates of foreign countries in China. The US government has recognized the cyber management condition of China. Therefore, it is good at using Chinese local social networks. American institutions functioning abroad in China all registered accounts in Sina blog, Sohu blog, Weibo, Douban, Renren, and so on. They all fulfill their destiny to develop public diplomacy in these Chinese local media. It shows that the US public diplomacy toward China is comprehensive and pragmatic.

\section{THE ANALYSIS OF WECHAT PUBLIC ACCOUNT OF THE US EMBASSY IN CHINA}

The information releasing in WeChat public account of the US embassy in China can be regarded as a typical representative of new media public diplomacy model. The information content is rich, and its releasing frequency is high. Besides, its impact is also growing. The US embassy's model can give China's new media public diplomacy some inspirations. However, the US also has some aspects to promote.

\section{Characteristic Analysis of US Public}

Diplomacy to China From WeChat Public Account of US Embassy in China

Comprehensive communication content, media and influence scope. American diplomats were at first slow to adopt social networking tools for public diplomacy, but now they make full use of those new tools (Rugh 2014: 112). The content of US new media public diplomacy in China is comprehensive, in which there are salons, lectures, and so on. Besides, the audiences who have participated in these activities contain all ages and classes. It means that there are Chinese elites and common people who are just interested in America.

Besides, it can be found on the official website of the US embassy and consulates in China that there are clear links to their homepage on every kind of new media platform, including global new media platform such as Facebook and Twitter, as well as Chinese local new media platform like Sina Weibo and Tecent Weibo.

Local new media usage. Today, American institutions in China have fully learned Chinese law and they can make full use of Chinese local new media effectively. The US embassy and consulates all have opened their official accounts in Chinese local new media such as Sina Weibo, Renren, WeChat public accounts, Douban, and so on. It brings them closer to ordinary Chinese people who will be more and more friendly with America. That is to say, the output form of American attitudes and ideology is more subtle, but the effect is better.

The diversity of audience. The characteristic is based on the cities in which embassies and 
consulates of the US are located. That is Beijing, Shanghai, Guangzhou, Shenyang, Chengdu, Wuhan, and Hong Kong. Especially in Beijing and Shanghai, there are Beijing American Center and Shanghai American Center which are set up by embassy and consulate of the US. In these two cities, activities are hold frequently and people's participation is high.

Taking Shanghai American Center as an example, as a part of Public Affairs Section, Consulate General of the US in Shanghai, it holds cultural and educational activities ${ }^{5}$.

According to the author's experience in Shanghai American Center, the people who participate in these activities contain young students, businessmen who often go abroad, teachers, and common people. Therefore, the diversity of audience is obvious in these two cities.

Two traits of information releasing. From the contents of the US new media public diplomacy toward China, there are differences in content and text style between official websites and social networking sites. The articles about American culture, education, society, and so on take a majority position in public account of the US embassy in China. Other articles are news about Sino-US relations and the tone of news is about the active friendship between two countries and it seems that US institutions avoid sensitive issues in bilateral relations. It is obvious comparing with the sensitive news in US embassy website.

It can be seen from the above that US public diplomacy to China in new media tends to be more pragmatic. The US public diplomacy to China changed from the extremely ideology with traditional media such as Voice of America to new media with less political contents. The transformation of international system and the development of China's economy promote the transformation. The rationality of the US public diplomacy to China and the friendship with China for a long time in the future take a majority in these factors.

Therefore, the communication of America to China catches a skill called "degree". That is to say, America sets different style position to different new media platform. It has formed a proper balance that the publishing of official information is authoritative and serious, as well as the information in new media platform is interesting and funny, therefore, it has made full use of new media's function.

\section{The Problems Faced by WeChat Public Account of the US Embassy in China}

The activities held by American embassy in China are usually located in Beijing and Shanghai, so embassy and consulates of the US have many other ways to propagandize.

Otherwise, the embassy can register another WeChat public account which dedicates to posting the information of activities on Beijing American Center. The original account could post more articles about America local customs and American people's daily life. In other aspects, the staff of embassy and consulates can hold a series of activities in different areas about promoting their country's culture and folk-custom. But before these activities, they should negotiate well with Chinese governments at all levels.

Today, the WeChat public account of the US embassy has operated gradually mature. However, making full use of the platform still has much room to promote.

Firstly, WeChat public accounts have a function of sending voice messages to subscribers. If subscribers reply a specialized character, they can receive related articles. However, the author does not find that the account of American embassy has used these functions. It can be improved in the future, consequently, making full use of the functions of WeChat public accounts can enhance the number of subscribers and the effect of public diplomacy can develop better. 
Secondly, the public account of the embassy can divide the work with subscription accounts and service accounts. Now, public account has created the user-defined menu and it is divided into "the Latest Activities", "Embassy Weibo", and "Embassy Video"6. To some extent, it promotes the development of public diplomacy target. Furthermore, it also can classify activities with different subjects, in that way, subscribers can find their interesting activity information effectively. It will make the public diplomacy more targeted.

\section{THE ENLIGHTENMENT OF NEW MEDIA PUBLIC DIPLOMACY}

With the large application of the Internet, the barriers to entry are significantly lowered. The 2.0 world is not limited to Westerners with broadband Internet connections. Mobile phones, which are more widely accessible than the Internet, provide both indirect and direct points of entry (Seib 2009: 137). With the development of modern communication technology, new media public diplomacy has gradually highlighted the significance of universality. After analyzing and comparing with public account of the US embassy, there are some enlightenments for China to develop new media public diplomacy.

\section{It Is the New Area to Develop Public Diplomacy With New Media, Such as WeChat Public Accounts}

The development of public diplomacy has a trend that the media platform is popular and diversified. As the development of technology, the media develops and evolves continuously.

From the history of the US public diplomacy toward China, its media using is changeable with different time. The initial public diplomacy is information transformation which means that the government is dominant; the elite of the society is the backbone; the general public is the foundation (Lei
2014: 02). Therefore, through using new media platform effectively, we can promote the positive national image to other countries' people and enhance the mutual understanding. In addition, there is an institution called Beijing American Center in the introduction of WeChat public account of the embassy. It is the place for cultural activities, educational resources, and offices which coordinate and support the cultural and educational exchanges between China and the United States ${ }^{7}$. It can inspire China's public diplomacy to foreign countries. For example, China also can establish China Center which belongs to Chinese embassies in foreign countries. The institution also can hold some lectures and salons to spread Chinese culture and spirits, breaking through the existing Chinese language teaching and the establishment of the Confucius Institutes.

Nowadays, new media platform like WeChat public account has become a new platform for the spreading of China's national image. The combination of new media and public diplomacy enhances the effect of national image's spread. As the number of WeChat's oversea audiences is growing, the number of Chinese foreign institutions' WeChat public accounts is increasing.

As the WeChat's internationalization has improved, the number of foreign audiences is also increasing. Therefore, the number of public accounts of Chinese foreign institutions is growing. It is obvious that the trend needs China government to promote Chinese new media technology overseas export, building China's digital infrastructure and international technology platform for the implementation of new media and public diplomacy [Center for Public Diplomacy Studies of BFSU (Beijing Foreign Studies University) 2012: 126].

\section{Developing Public Diplomacy With New Media Is a Method Which Has a Character of Subtle Influence}

Developing public diplomacy with WeChat public 
accounts needs to play its character called "subtle influence". Today, many old people have become the audiences of WeChat. So it is more and more important to develop public diplomacy in this way.

Although public account of embassy of the US is managed officially, the contents posted are not serious. Words in public account are humorous and funny, therefore, it is close to the feeling of Chinese people. For China's foreign institutions, the staff should be familiar with some kinds of new media platform. Chinese government should pay more attention to the personnel training about new media. Chinese diplomatic staff should master the function of mew media, so as to develop public diplomacy and spread Chinese soft power.

\section{New Media Public Diplomacy Can Force the Establishment of China Public Diplomacy Strategy}

There are more and more methods and ways to develop public diplomacy in Internet era, and there are not barriers in the relationship between government and individuals. The connection is real-time and effective.

When any international relations actor is promoting cyber diplomacy, in other words, when it plans to put the Internet as diplomatic tool, it must make good preparation for overall strategic adjustment which contains the change of national interest cognition (Shen 2013: 282). For the United States, cyber diplomacy is a kind of "flexible" diplomacy. Its effect on promoting the US foreign policy is better than other forms of diplomacy and it is more efficient (Wang 2015: 180). The current China's new media diplomacy has not formed its advantages and characteristics. Therefore, it is essential to formulate a long-term development strategy of public diplomacy in new media time. The new media can play a role in affecting more people and mobilizing more power. Besides, the new media public diplomacy strategy has a chance to become soft power development strategy in the process of implementation depending on the experience of diplomatic institutions in new media public diplomacy practice.

\section{New Media Public Diplomacy Has the Potential to Be a Useful Supplement to the Practice of China's Diplomatic Theories}

With national strength enhancing, China participates in international affairs more and more extensively. In the face of the complex world situation, China needs to formulate effective diplomatic strategy. The positive development of public diplomacy to foreign countries can promote the implement of national strategy like "Belt and Road Initial" and "a new model of major-country relations between China and the US". Chinese foreign policy and strategy could be realized in the practice of public diplomacy.

Therefore, a comprehensive public diplomatic strategy is a driving force for the implementation of the diplomatic strategy. To think of Chinese future strategy, the development of public diplomacy should serve for Chinese diplomatic strategy closely.

It can be seen from above. The effect of WeChat public account of the US embassy in China is obvious. It gives China new media public diplomacy much enlightenment. On the one hand, the establishment of Chinese diplomatic institutions' official Weibo and WeChat public accounts can be more close to common people and these foreign institutions have more chances to promote Chinese image and spirits which can break through the current single public diplomacy model of Chinese language education in Confucius Institute. Therefore, the relevant foreign affairs institutions need to strengthen the study of new media public diplomacy.

The most important characteristic of developing public diplomacy is "new". That is to say, it will leave a deep impression in foreign countries' people with the most popular media communication. It can be found from the trend in the history of the US public 
diplomacy toward China. From the "Voice of America" to the official accounts in social networks of embassy and consulates in China, the US attaches importance to the media communication in public diplomacy to China. But the information posted by embassy and consulates of the US seems to avoid the tender subject like democracy and human rights. It cannot remove the possibility of longtime strategy to influence Chinese people in a potential way by public diplomacy, which may push forward the color revolution in China.

On the other hand, the official website of the PRC's embassy in America can establish the links of social media accounts such as Facebook and Twitter. If Chinese foreign institutions can register their official page in social networks which is popular in foreign countries, it could enlarge the foreign audiences and will be beneficial to the development of Chinese foreign public diplomacy. Chinese embassies and consulates should increase the homepage maintenance personnel properly. The hard condition should be improved for foreign public diplomacy from institution to personnel assignment.

\section{CONCLUSIONS}

The popularity of new media such as WeChat public platform provides a new path for the development of public diplomacy in the world. With the overall enhancement of China's comprehensive national power, the promotion of China's international influence, Chinese government should give more funds and personnel to the development of public diplomacy. In a series of foreign strategy construction such as the Belt and Road and a new model of major-country relations, it is needed to show China's attractiveness in public diplomacy details. These diplomatic behaviors may be a stepping stone of successful Chinese diplomatic strategy in the future. Besides, in some aspects of diplomatic theories, national image, and so on, the development of new media public diplomacy also can bring new enlightenment.

Therefore, a country not only can show the "hard" aspect of national strength with the new media platform, but also can make the common people and elites agree with its "soft" aspect like culture and ideology (Tan 2011: 226).

\section{Notes}

1. "New Media." Wikipedia. Retrieved (https:// en.wikipedia.org/wiki/New_media).

2. U. S. Department of State. 1987. Dictionary of International Relations Terms. P. 85.

3. The author will attribute the information about American politics, economy, culture, and society to the category called "The situation of America".

4. Table 1 and Figure 1 are collated by author according to the information released by the public account of the US embassy.

5. It can be seen from the official publicity materials of Shanghai American Center in detail.

6. The author observed the WeChat of the US embassy in China on August 25, 2015.

7. "Beijing American Center." Retrieved September 21, 2015 (http://beijing.usembassy-china.org.cn/bac.html).

\section{References}

Center for Public Diplomacy Studies of BFSU (Beijing Foreign Studies University). 2012. Annual Report of China's Public Diplomacy (2011/2012). Beijing: Current Affairs Press.

Dong, Q. L. and R. P. Sun. 2012. "New Media Diplomacy: A New Diplomatic Revolution?" International Review 5:31-32.

Gilboa, E. 2008. "Searching for a Theory of Public Diplomacy." The Annals of the American Academy of Political and Social Science 616(1):55-57.

Lei, W. Z. 2014. "New Media and Public Diplomacy: Making Good Use of Voice From Common People." China Youth Daily, April 9, p. 02.

Rugh, W. A. 2014. Front Line Public Diplomacy: How US Embassies Communicate With Foreign Publics. New York: Palgrave Macmillan.

Seib, P. 2009. Toward a New Public Diplomacy: Redirecting U.S. Foreign Policy. New York: Palgrave MacMillan.

Shen, Y. 2013. The US National Cybersecurity Strategy. Beijing: Current Affairs Press. 
Tan, Y. Z. 2011. The Strategy of the United States Public Diplomacy Towards China. Beijing: Current Affairs Press.

Wang, X. F. 2015. Cyber Strategy: A New Pillar of U.S. National Strategy. Shanghai: Fudan University Press.

Zhou, X. Y. 2013. "Public Diplomacy in the Cake." World Affairs 9:52.

\section{Bio}

Zhao Geng, post-graduate student, School of International Relations and Public Affairs, Shanghai International Studies University, China; research fields: Sino-US relations, public diplomacy, cyber diplomacy. 